\title{
Monitoring of Welding Process Parameters in Gas Tungsten Arc Welding of Carbon Steel Weldments
}

\author{
Regita BENDIKIENE*, Saulius BASKUTIS**, Jolanta BASKUTIENE***, \\ Lina KAVALIAUSKIENE**** \\ *Department of Production Engineering, Kaunas University of Technology, Studentu str. 56, LT-51424 Kaunas, Lithuania, \\ E-mail: regita.bendikiene@ktu.lt \\ **Department of Production Engineering, Kaunas University of Technology, Studentu str. 56, LT-51424 Kaunas, Lithuania, \\ E-mail: saulius.baskutis@ktu.lt \\ ***Department of Production Engineering, Kaunas University of Technology, Studentu str. 56, LT-51424 Kaunas, Lithuania, \\ E-mail: jolanta.baskutiene@ktu.lt \\ ****Department of Production Engineering, Kaunas University of Technology, Studentu str. 56, LT-51424 Kaunas, Lithuania, \\ E-mail: lina.kavaliauskiene@ktu.lt
}

crossref http://dx.doi.org/10.5755/j01.mech.25.1.22158

\section{Introduction}

The gas tungsten arc welding (GTAW) is based on the electric arc established between a non-consumable tungsten electrode and the parts to be joined. This very versatile high quality process widely and extensively used as welding method for parts of carbon and mild steel, aluminium, titanium, copper, nickel or magnesium alloys as well as components of stainless steel [1-3].

In general, the quality of a weld is characterized by parameters such as dimensions of penetration and structure of the material in the welded region. The structure, chemical composition as well as weld pool geometry and heat-affected zone (HAZ) have huge influence on mechanical properties of the welded joints. HAZ dimensions and structure is a function of base metal and the welding conditions which determine the thermal cycle. The effects of welding heat input per unit length on weld of low carbon steel geometry were examined by Clark [4]. It was claimed that heat input can be used as the independent variable for controlling the dimensions of the weld bead geometry and the weld with the same value of heat input has identical cooling time and identical microstructure of HAZ and hence HAZ properties for a given metal regardless of the values of welding current, arc voltage and travel speed. However, other researchers [5-7] have claimed that welding variables such as current, voltage and travel speed have individual influence on output variables of the weld, first of all, HAZ dimensions, weld bead geometry and microstructure.

The main disadvantages of GTAW are a large weld bead size and thermally induced distortion. It is known that thermal parameters of the welding process depend to a large extent on arc voltage, welding current and travel speed. Welding current is the most influential parameter in GTAW process and has direct influence on weld pool shape, on the depth of fusion and total quality of the weld. An increase in welding current increases penetration and reinforcement. Many researchers have found that next to current, travel speed is one of the most important factors controlling heat input and dimensions of the weld bead [8-10] when joints are made of low alloyed steel. The dimensions of the different HAZ zones decrease with increase the travel speed. Increased travel speed for the constant arc voltage and current reduces the heat input, the width of weld bead and decrease the weld reinforcement. Welding voltage has direct influence on the depth of penetration. High welding voltage determines wider and less deeply penetrating welds than lower voltages.

Tasalloti et al. [11] have reported in their work on effect of different welding wires and the torch weaving technique on the microstructure and hardness of plain carbon steel welded joints. It was determined that sharp increase in hardness on the ferritic side and around the fusion interface is caused by presence of martensite formation within this zone. Maksuti et al. [12] established the correlation between microstructure and hardness of two-pass arc welds of line pipe mild steel. The influence of shielding gas on microstructure, penetration and mechanical properties on tungsten arc welding of steel was examined by Durgutlu [13]. The investigations revealed that penetration depth and weld bead width as well as average grain size in the weld increases with increasing hydrogen content in argon as a shielding gas. The optimization of weld pool geometry in the tungsten inert gas welding by using modified Taguchi method was studied by Juang and Tarng [14]. In this study welding current, travel speed, flow rate and arc gap have been analysed. As a result, four quality parameters corresponding to the width and height of front and back of the weld pool were evaluated. The influence of heat input on the microstructure and mechanical properties of GTAW welded steel joints was investigated by Kumar and Shahi [15]. It was determined that the joints made using low heat input exhibited higher ultimate tensile strength than those welded with medium and high heat input. Moreover, it was found that the extent of grain coarsening in the HAZ increased with increase in the heat input.

It is evident that the dimensions of the weld and herewith the quality of welded joints greatly depend on welding process parameters such as welding current, arc voltage, filler rod feed rate, travel speed, shielding gas flow, etc. Thus, it is very important to control weld pool and HAZ formation process and predetermine dimensions and structure of both areas. Nonlinear and multi-objective mathematical models were developed to determine the welding parameters corresponding to optimum weld pool geometry [16]. The mathematical relationships between input control variables (current, travel speed, gas flow rate, gap) and weld pool parameters were obtained. Visual monitoring systems 
are used in industry for remote monitoring of welding processes in automated applications. Unfortunately, the imagine quality obtained from visual monitoring systems is often not sufficient to evaluate the joint quality due to the high intensity of light emitted by the arc. Real time vision-based control of weld pool size was studied by Lucas et al. [17]. A correlation-based image analysis algorithm has been developed, which was configured to operate with a number of different welding parameters. This allowed successful upper surface weld pool regulation via feedback control algorithm. It was demonstrated how this approach may be used to improve weld area uniformity. Visual sensing system for weld shape quality control during GTAW with filler rod was investigated by Chen et.al $[18,19]$. Arc welding method using with a non-consumable electrode and a consumable filler rod, wherein the transfer of metal to the weld pool occurs in successive droplets from filler rod is described by Fortain et al. [20].

In previous research weld control possibilities using consumable electrode and piezoelectric sensor in metal arc welding of low alloyed carbon steel was discussed [15]. Piezoelectric accelerometers are widely used for general purpose acceleration, shock and vibration measurements. They are self-generators not requiring external power sources with large output signals and comparatively small sizes. They are available with very high natural frequencies and are therefore suitable for high-frequency applications and shock measurements [22, 23].

The intension of the presented study is to show the possibilities to monitor and control the automatic GTAW process using additional filler rod as well as to investigate the evolution of microstructure and the mechanical characteristics of carbon steel weldments under the different welding parameters. In order to monitor welding process piezoelectric sensor during the experimental procedures has been used. In addition, the comments on formation of heat affected zone and weld pool as a result of welding parameters also have been discussed in the paper. Finally, the data acquisition and processing controller was developed.

\section{Materials and methods}

The standard carbon steel as a base metal and ER70S-6 filler rod with diameter of $1.6 \mathrm{~mm}$ has been chosen for the experiments. The nominal chemical composition and mechanical properties of base material as well as filler rod are presented in Table 1.

Chemical compositions of base material and filler rod used in this study

\begin{tabular}{|l|c|c|c|c|c|c|}
\hline \multirow{2}{*}{ Materials } & \multicolumn{5}{c|}{ Chemical composition, \% } \\
\cline { 2 - 7 } & $\mathrm{C}$ & $\mathrm{Mn}$ & $\mathrm{Si}$ & $\mathrm{P}$ and S & $\mathrm{Cr}, \mathrm{Ni}, \mathrm{Mo}, \mathrm{Ti}, \mathrm{Cu}$ & $\mathrm{Cu}$ \\
\hline Steel grade S275JR* & 0.21 & 1.50 & 0.05 & 0.040 & - & 0.55 \\
\hline Filler rod ER70S-6** & $0.06-0.14$ & $1.60-1.80$ & $0.80-1.20$ & $\leq 0.025$ of each & $\leq 0.15$ of each & - \\
\hline $\begin{array}{l}* \text { EN 10025-2:2004 } \\
\text { ** Used for welding of carbon steel and low alloy steel structures of relevant strength grade. }\end{array}$ \\
\hline Properties & Yield strength, MPa & Tensile strength, MPa & \multicolumn{2}{c|}{ Elongation, \% } \\
\hline S275JR & \multicolumn{2}{|c|}{275} & $410-500$ & 23 \\
\hline
\end{tabular}

This type of filler rod is used to weld small diameter pipes, boilers and tubing as well as sheets of similar metals. The base material was machined into $40 \times 15 \times 200 \mathrm{~mm}$ size rectangular samples to serve as the weld blanks. The surfaces of the weld blanks before welding were chemically cleaned with acetone to eliminate surface contaminations and then they were dried in still air. Three types of samples were produced and used for tests: solid metal - for formation of build-up welds and U-grooved samples; solid metal samples were subjected to butt weld with maximum gap of $2 \mathrm{~mm}$ between plates. Build-up welds are mostly applied for kind of repair operations. In cases when strong weld is needed, groove weld might be applied. Butt joints are used where high strength is required. They are reliable and can withstand stress better than any other type of weld joint. To achieve full stress value, the weld must have 100 percent penetration through the joint. This can be done by welding completely through from one side.

The welding operation was carried out using the GTAW process by means of filler rod and argon (with $2 \%$ of He) shielding gas. The shielding gas flow rate was kept constant at 12 liter/minute. It provides an excellent shielding of the molten weld pool and also has a large influence on the proper arc ignition and relevant arc stability. The welding setup is shown in Fig. 1, weld processing parameters which influence the quality of weld were tested and are indicated in Table 2.

Weld processing parameters

\begin{tabular}{|c|c|c|c|c|}
\hline Welding mode & Welding current, A & Arc voltage, $\mathrm{V}$ & Travel speed, $\mathrm{mm} / \mathrm{min}$ & Feed rate, $\mathrm{m} / \mathrm{min}$ \\
\hline 1 & 35.1 & 14.7 & 58.8 & 0.5 \\
2 & 68.4 & 15.2 & 114.6 & 1.5 \\
3 & 76.9 & 17.2 & 129.0 & 1.7 \\
4 & 82.4 & 18.1 & 138.0 & 1.9 \\
5 & 109.8 & 20.2 & 184.2 & 2.5 \\
6 & 130.9 & 21.0 & 219.6 & 2.9 \\
7 & 159.0 & 22.2 & 266.4 & 3.6 \\
8 & 170.5 & 24.3 & 285.6 & 3.8 \\
9 & 200.6 & 25.7 & 336.0 & 4.5 \\
10 & 240.8 & 27.5 & 402.0 & 5.4 \\
\hline
\end{tabular}




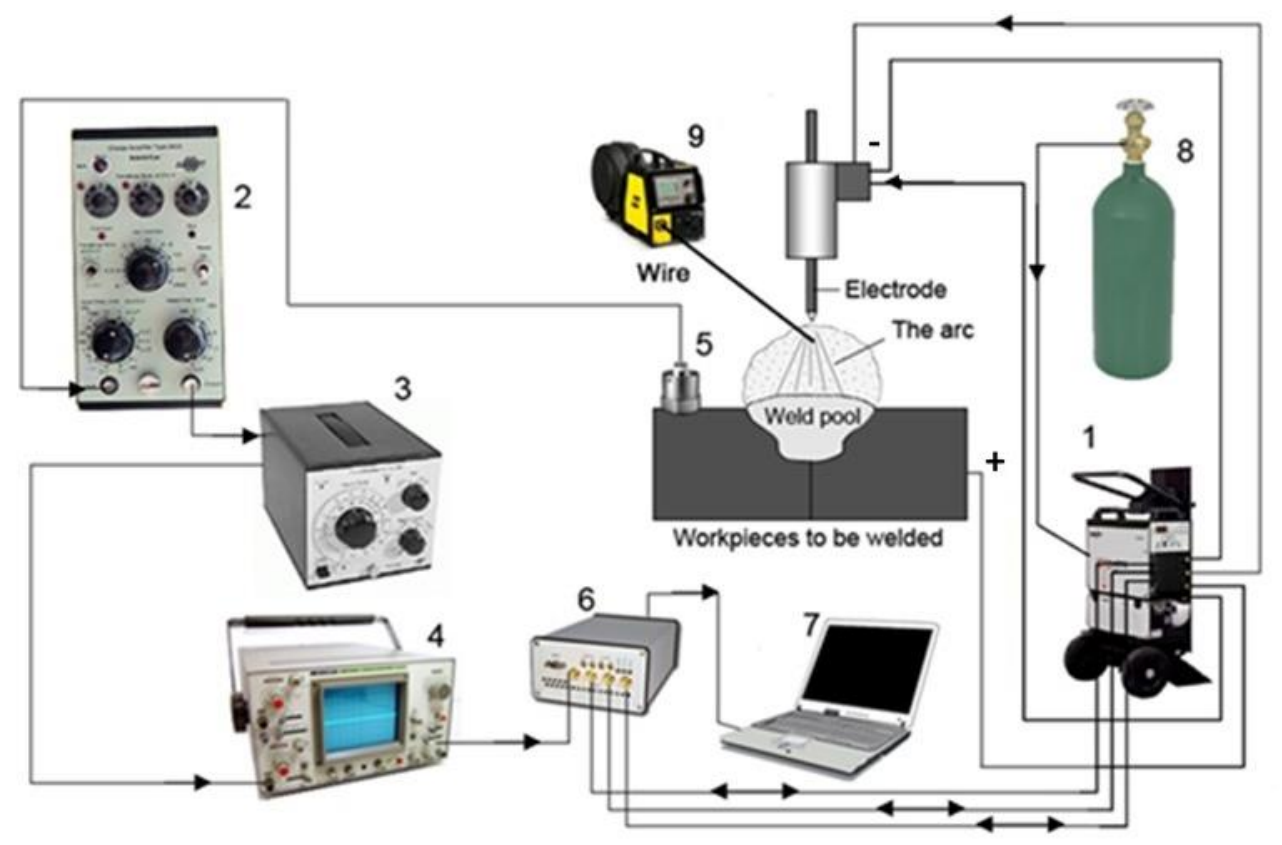

Fig. 1 GTAW setup: 1 - welding machine, 2 - LF charge amplifier, 3 - tunable band pass filter, 4 - oscilloscope, 5 piezoelectric sensor, 6 - signals' acquisition and processing device, 7 - computer, 8 - shielding gas tank, 9 - wire feeder

The welding with non-consumable electrode requires relatively large density welding current, therefore, small diameter filler rod $(1.6 \mathrm{~mm})$ which is fed into electric arc by a relatively high feed rate should be used.

To ensure relevant welding process, it is important to control the duration of the liquid drop formation, passing the arc length and dropping to the weld pool, as well as the dimensions of the formed drop and variation of the electrical parameters. Controlling the process of the filler rod transfer into the melted metal pool, which has the direct impact on the weld quality, the precise registration of the above mentioned parameters is of great importance. To monitor and control the metal transfer process during the experiments the accelerometer (Brüel\&Kjǽr, 4367) was used. The accelerometer 4367 was chosen because of better overall characteristics than any other type of vibration transducer, and particularly high stability to temperature alternations and base strain sensitivity. The application area of this sensor, made of lead zirconate titanate-soft (Pz 23), is general shock and vibration measurements as well as vibration testing and control. The sensor consists of three piezoelectric elements and three seismic masses arranged in a triangular configuration around a triangular centre post. They are held in place by a clamping ring that isolates the configuration from the base. During the welding process the droplet from the filler rod transfers into the weld pool and excite vibrations. Due to vibrations the piezoelectric elements produce a charge that is collected between the housing and the clamping ring. Charge signal passes through the signals' processing track and is registered by oscilloscope. The relatively high Curie temperatures $\left(>350^{\circ} \mathrm{C}\right)$, low mechanical quality factor, high voltage $(2 \mathrm{mV} / \mathrm{ms}-2$ or $20 \mathrm{mV} / \mathrm{g})$ and charged sensitivity ( $2 \mathrm{pC} / \mathrm{ms}-2$ or $20 \mathrm{mV} / \mathrm{g})$, wide frequency range $(0.1-9700$ $\mathrm{Hz}$ ) at elevated temperatures (Ferroperm Piezoceramics $\mathrm{A} / \mathrm{S}$ ) are general specifications of $\mathrm{Pz} 23$. Therefore, it was possible to place the piezoelectric sensor, which base is made of titanium, close to the welding pool $(\approx 50 \mathrm{~cm})$.
During the welding procedure the filler rod in the form of a wire was fed into the arc automatically. An automatic GTAW process ensures to maintain constant distance between the non-consumable electrode and welding surface as well as between the tip of the wire and electrode. The molten filler rod can be transferred to the weld pool by three transfer modes: short circuit transfer, globular transfer and spray transfer. The size and transfer frequency of the droplets into the weld pool depends on welding current, the filler rod feed rate, rod diameter, distance between rod and electrode, and finally on the distance between rod and welding surface.

The tip of the consumable filler rod was permanently guided and held in position at a distance of $2 \mathrm{~mm}$ or even less from the tip of the non-consumable tungsten electrode. Anyway, the tip of the wire should not come into contact with the electrode. The distance between the electrode and the welding surface was about $3 \mathrm{~mm}$. The filler rod feed rate ranging from 0.5 to $5.4 \mathrm{~m} / \mathrm{min}$ has been chosen according to the diameter of the filler rod and current strength. On increasing current strength above 250 A (mode $10-240.8$ A) droplets flow as a continuous liquid stream. The feeding rate of the filler rod is somewhat independent of the welding current, thus allowing a variation in the relative amount of the fusion of the base metal and the fusion of the filler rod [3]. Therefore, the control of dilution and energy input to the weld can be achieved without changing the size of the weld.

GTAW welding was carried on each type of samples under different processing parameters: current, voltage and travel speed. The specimens were welded at ambient temperature $18^{\circ} \mathrm{C}$ under the travel speed from $58.8 \mathrm{~mm} / \mathrm{min}$ up to $402.0 \mathrm{~mm} / \mathrm{min}$. (Table 2 ). The signal data acquisition and processing device (4 inputs: arc voltage, welding current, wire feed rate and piezoelectric sensor signal) and software application have been developed and used in the welding process analysis (Fig. 2). 


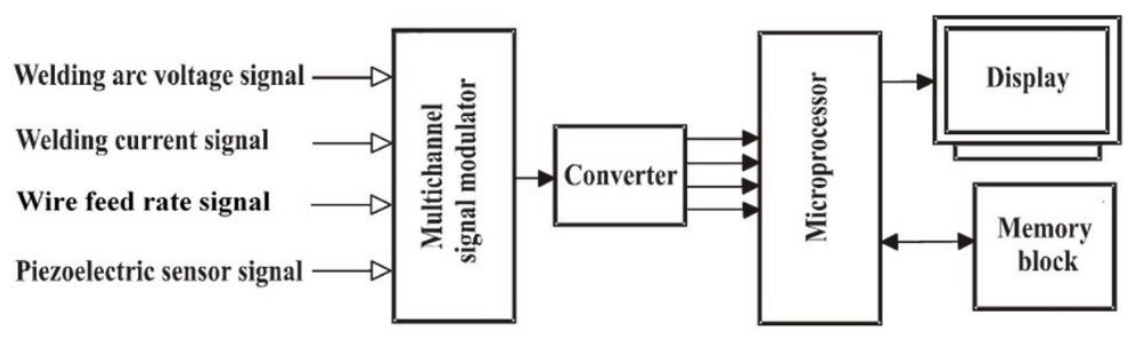

Fig. 2 Block diagram of signals' data acquisition and processing device

The data acquisition device comprises corresponding sensors for filler rod feed rate, welding current strength, arc voltage and piezoelectric sensor signals measurement and four signal amplifiers. The input range of used piezoelectric sensor is: 0 to $1 \mathrm{~V}, 0$ to $10 \mathrm{~V}$ and 0 to $100 \mathrm{~V}$.

After welding, all the samples were cleaned and cut at perpendicular direction into the segments for further hardness test and micro analysis. Sections for macro and micro analysis were prepared transversely to the welding direction using standard techniques of mechanical grinding, polishing to near a mirror finish and etching using $3 \%$ Nital solution. Examination of macrographs was done by means of a Nicon Eclipse 1000 optical microscope with magnification from $50 x$ to $100 x$.

Hardness measurements of the welded joints (base metal-HAZ-base metal) were accomplished on three types of samples (build up, U-grooved and butt weld) using NanoHardness Tester developed by CSM Instruments, Switzerland employing a standard load of $49.050 \mathrm{~N}$ with diamond indenter; for $10 \mathrm{~s}$ dwells period at $0.7 \mathrm{~mm}$ intervals, across and along the weld at the location of $2 \mathrm{~mm}$ from the weld surface. All the tests were conducted at the ambient temperature in the laboratory (at $20 \pm 2 \mathrm{C}$ and $50 \pm 5 \%$ relative humidity).

\section{Results and discussions}

The results showed that the conditions of the filler rod metal transfer into the weld pool, determined by corresponding electrical parameters, first of all welding current, as well as wire diameter and feed rate, distance between wire and electrode as well as distance between wire and welding surface have a significant influence on the weld quality and HAZ formation process. Both distances, welding current, and the filler rod feed rate are the key parameters determining the droplet transfer period ant its size. On decreasing the distance between filler rod and non-consumable tungsten electrode droplet size decreases, herewith the metal transfer frequency into the weld pool increases.

The transfer frequency and the size of the droplets from the molten end of the consumable wire to the weld pool have been registered by the piezoelectric sensor. Fig. 3 shows the curves as waveforms of the signals from the piezoelectric sensor. Due to the stream flow transfer of the wire metal into the weld pool (small droplets are almost simultaneously in connection with the tip of the wire and the weld pool), waveforms showed negligible variations of the signal in the recorded oscillograms (Fig. 3).

Whereas, relatively large size droplets generate considerable variations of the signal, which is registered by the piezoelectric sensor. Comparing the waveforms of modes $4-10$ with the mode 2 it is evident that the transfer period of the droplet becomes shorter and shorter and the droplet is smaller and smaller, as less falling mass of the drop causes smaller charge from the piezoelectric elements. The obtained signal amplitude and duration allows evaluating the size of the droplets and its transfer frequency into the weld pool. If both, the welding current and the filler rod feed rate increases the transfer period and droplet mass reduces.

As droplet size and transfer frequency mainly depends on electrical welding parameters and filler rod feed rate, these parameters can be monitored and controlled in order to obtain desired weld pool geometry and HAZ dimensions. Correlation between droplet transfer period to weld pool and welding current is presented in Fig. 4.

Different part of weldment experiences different heat inputs from one region to another, resulting in the formation of three distinct regions: weld zone, heat affected zone (HAZ) and unaffected base metal. Weld metal or fusion zone undergoes melting and solidification, evolution of macro and microstructure is one of the stressed issues of this research [24]. HAZ depth dependence on welding modes is shown in Fig. 5.

The geometry of HAZ mainly depends on metal transfer mode. The relatively high current results the drop transfer of the melted filler rod. The size of the drops depends on the current, as well as distance between tungsten electrode and welding surface. By increasing the current and decreasing the said distance it is possible to ensure liquid bridge transfer of the filler rod into the weld pool. The size of the droplets influences the metallurgical processes and overheats of the weld pool. The weld pool overheat is more rapid under relatively large droplet of the melted filler rod. As can be seen from Fig. 5 the depth of HAZ is negligible within the welding modes 1 and 2 when welding current is relatively low (Table 2), however welding current is relatively high (modes 9 and 10) the depth of HAZ considerably increases from 0.01 up to $5.45 \mathrm{~mm}$.

The hardness values of the weldments under varying welding parameters are presented in Fig. 6; it can be seen that the HAZ is associated with a reduction in hardness: hardness decreases from a maximum in the central part of the fusion zone and descending reaches a minimum value in the base metal [25].

Tendency of values distribution for different welding modes are the same. For the fusion zone, hardness values alternate from $218 \mathrm{HV}$ to $277 \mathrm{HV}$, for HAZ these values are in the range between $160 \mathrm{HV}$ and $190 \mathrm{HV}$, hardness of base metal reaches $155 \mathrm{HV}$. This can be explained by the formation of primary or Widmannstätten structure in the weld zone, concerning to the extreme cooling rates.

The cross-sectional macrographs showed that heat input Q influences joint geometry, i.e. weld width and weld penetration. The heat input supplied by the arc depends on arc voltage, weld current and travel speed and can be expressed by the following equation [4]: 


$$
Q=\frac{\text { Voltage }(V) \times \text { Welding current }(A) \times 60}{\text { Welding speed }(\mathrm{mm} / \mathrm{min}) \times 1000} \times \text { Efficiency factor, }
$$

where: $Q$ is heat input $[\mathrm{kJ} / \mathrm{mm}]$ and efficiency factor equal to 0.6 (for GTAW welding).

Macrograph observation of all welds obtained using different welding modes showed that the weld macrostructure is free from defects and good penetration is achieved. Penetration and depth of HAZ are influenced especially by the welding current. The optical images reveal primary Widmannstatten structure; the single crystals - dendrites, formed from the boundary of HAZ and weld zone are easily recognizable. Formation of dendrite structure gives a good indication of the thermodynamic processes during liquid metal solidification. In general, the crystals grow towards to the cooling surface (Fig. 7).

Therefore, the front of solidification, at the same time, the orientation of the crystals spins during crystallization process. The fact that the growing rate of crystals has its maximum value just below the temperature of solidification means that the crystals spinning upwards from the sides are dominating related to those growing up from the bottom part.
Very flat weld seam is observed in U-groove sample obtained using welding mode 10 (Fig. 8); crystals orientated nearly parallel.

The cooling influenced by the ambient temperature gives formation of less dendritic and more globular crystal structure near very top of the weld seem - the rate of crystal formation has its maximum value at a lower temperature than the rate of crystal growth. The difference between these rates sometimes can cause formation of weld defects, such as impurities and dissolved air. The orientated crystallization tends to press the impurities and bobbles in forefront of solidification zone, so defects especially air bobbles can be caught beyond the top.

Another example of crystal growth is clearly seen in Fig. 9; the crystals from the opposite sides nearly meet each other in the central part of weld zone. That means that any impurities possibly caught in the meeting line of two solidification fronts, could lead to the formation of weakness, most often brittleness.

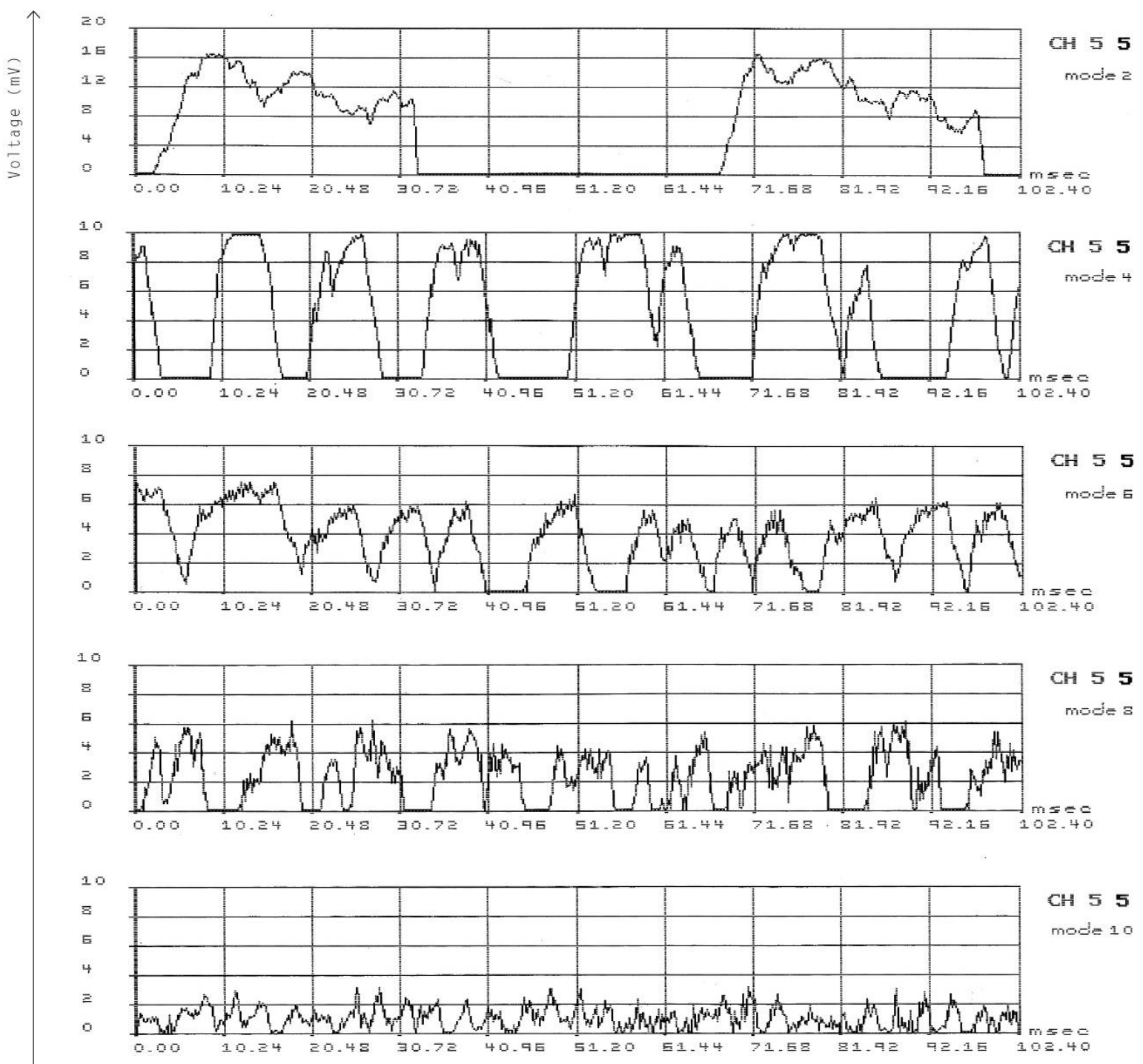

Fig. 3 Waveforms of piezoelectric sensor's signal under different welding modes 


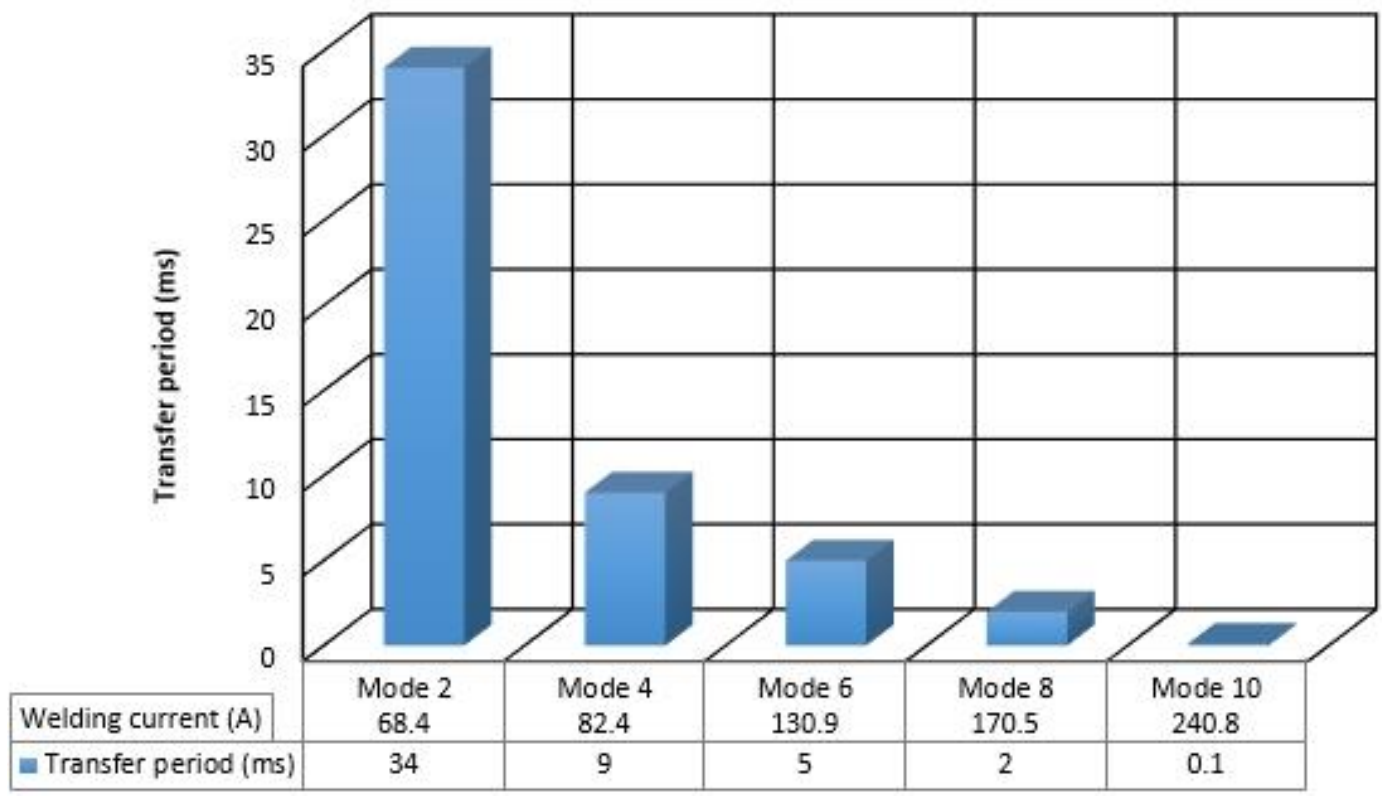

Fig. 4 Correlation between droplet transfer period and welding current

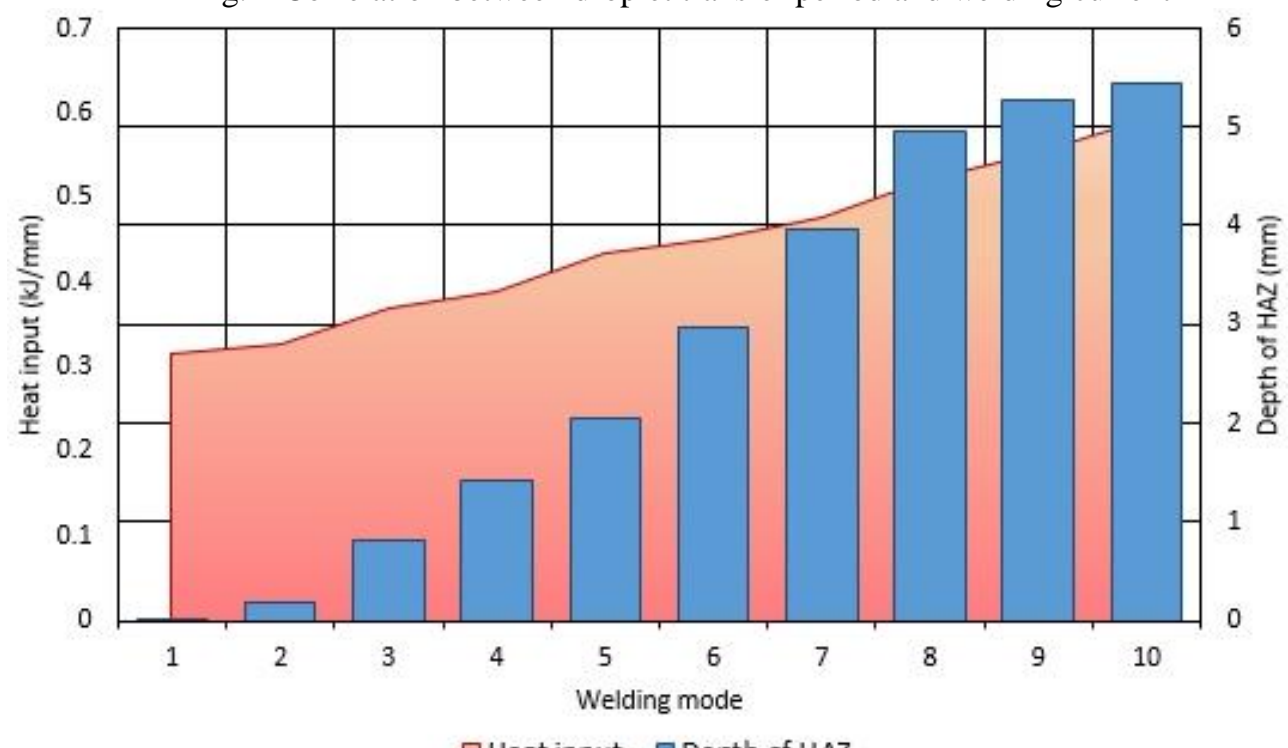

$\square$ Heat input $\square$ Depth of HAZ

Fig. 5 Influence of welding mode on heat input rate and depth of HAZ

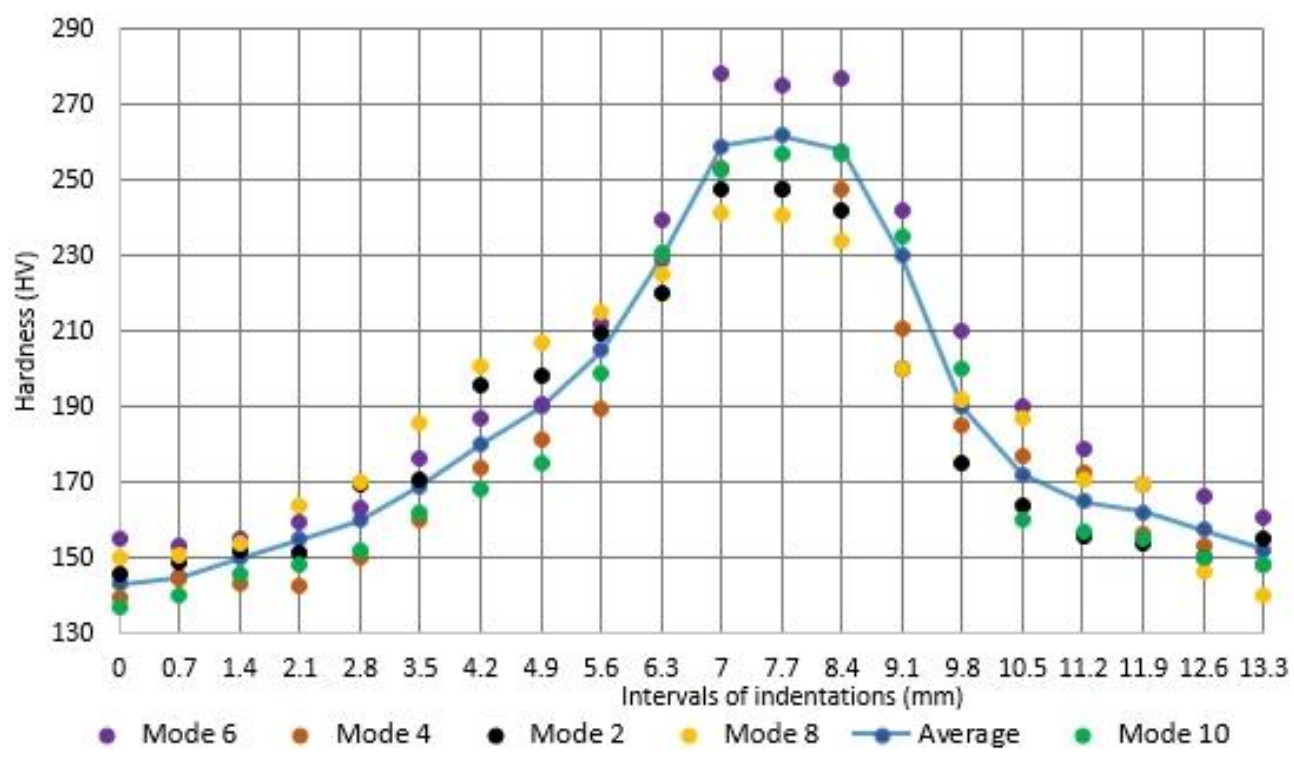

Fig. 6 Variation of hardness across the weldments (butt welds) 


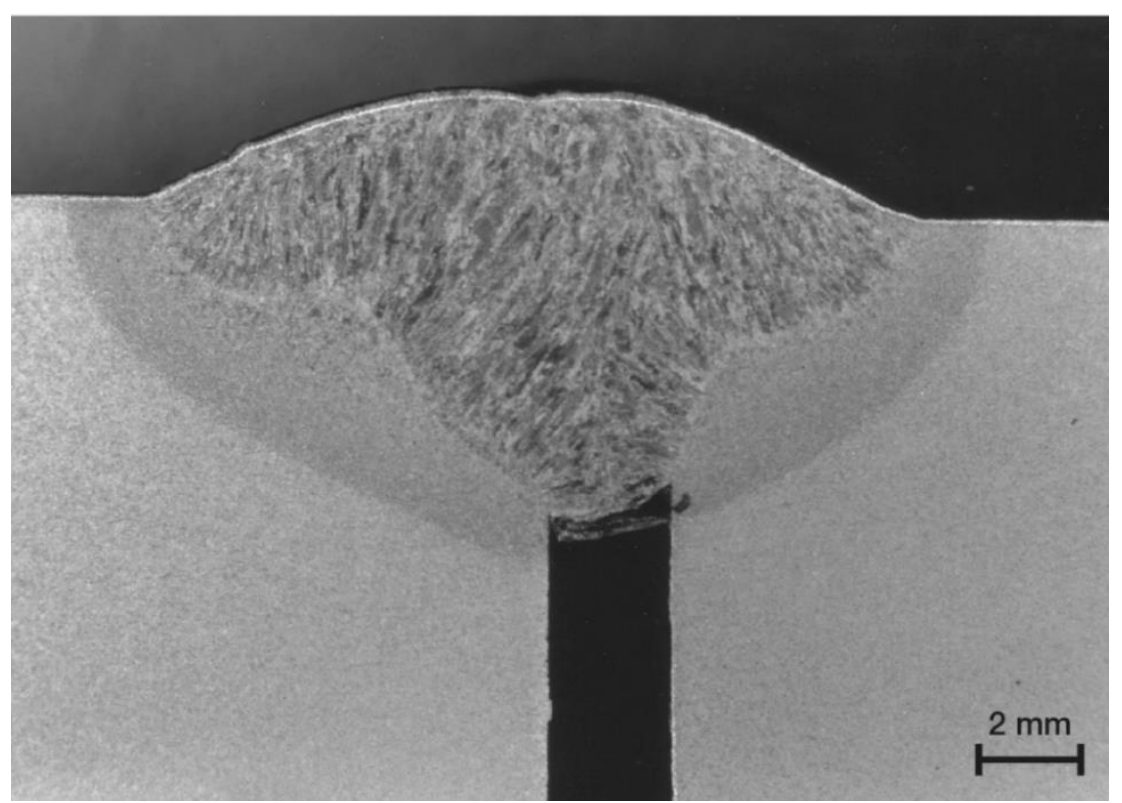

Fig. 7 Optical macrograph showing direction of crystal growth (butt weld)

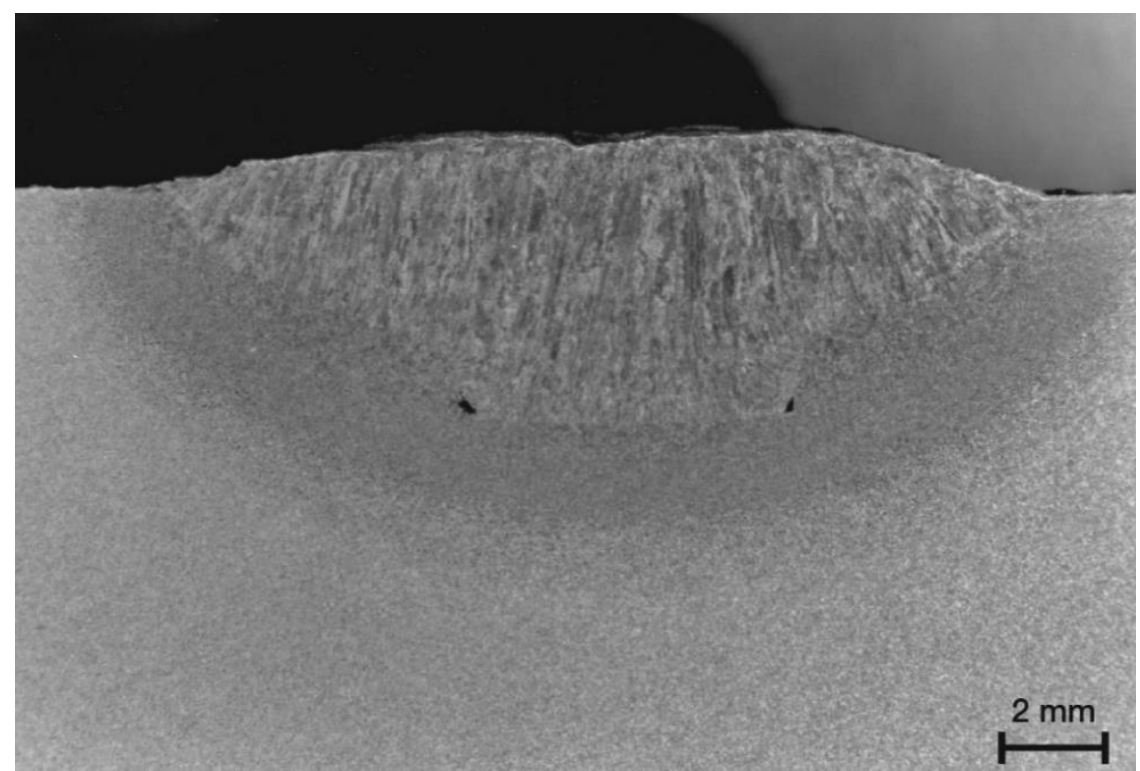

Fig. 8 U-grooved weld seam

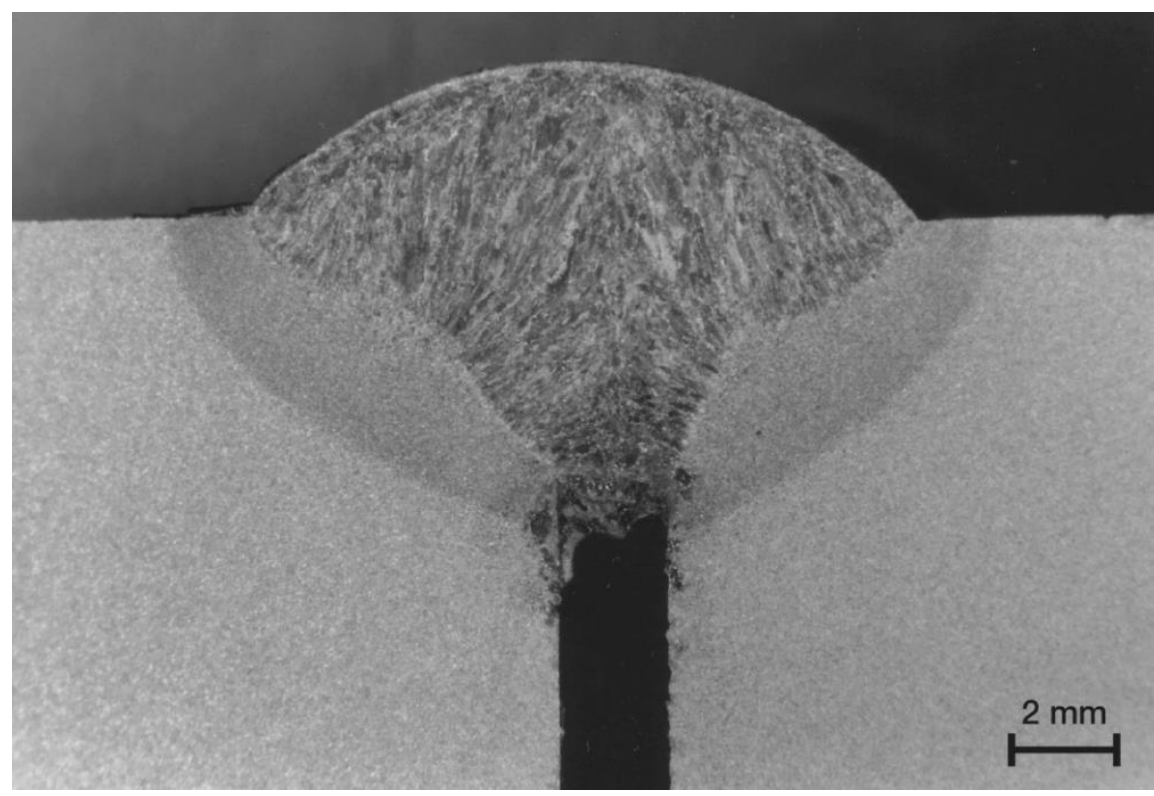

Fig. 9 Meeting of opposite solidification fronts 


\section{Conclusions}

1. The effect of different welding parameters on mechanical and metallurgical properties of carbon steel joints was examined. The welded joints showed that crystal orientation and shape in the weld zone depend on thermodynamic processes during solidification and welding mode.

2. Due to increasing the welding current and decreasing the distance between the filler rod and electrode, the droplet size decreases, herewith the transfer period of the metal droplet into the weld pool decreases.

3. Application of piezoelectric sensor for monitoring of HAZ, weld bead geometry and microstructure gives the possibility to control overall parameters of welding process. Droplet size distribution and rate of transfer of droplets to the molten metal pool are affected by arc temperature, distance between electrode and welding surface, and filler rod feed rate.

4. Gap between base metal as well as increased welding current initiate formation of opposite solidification front in butt weld joints, which can cause appearance of welding defects in the central part of weld.

5. The experimental results showed that the depth of HAZ increases with the increase in arc voltage and welding current. It gives additional information about heat distribution

6. Piezoelectric sensor used for the welding process monitoring and control provides possibility to select the optimal welding mode depending on the weldments being welded. The modes 2 and 3 are the most suitable when tack welds or coupling of the parts is necessary, the modes 7 and 8 are applicable for the tight joining or leak-proof welding, e.g. for pipes, storage tanks, whereas mode 9 and especially mode 10 are suitable for a repair welding during the renovation or restoration of the worn parts.

\section{References}

1. Pires, J. N.; Loureiro, A.; Bolmsjo, G. 2006. Welding robots, technology, system issues and applications. Springer.

2. Singh, R. 2012. Applied welding engineering: processes, codes and standards. Elsevier Inc, Waltham (MA).

3. Kou, S. 2003. Welding metallurgy. John Wiley \& Sons, Inc., Hoboken, New Jersey.

4. Clark, J. 1985. Effect of process parameters on dimensions of weld bead and heat-affected zone, Journal of Materials Science \& Technology 1: 1069-1080. http://dx.doi.org/10.1179/mst.1985.1.12.1069.

5. Chen, S.; Zhang, S.; Huang, P. et al. 2016. Droplet transfer in arcing-wire GTAW, Journal of Manufacturing Processes 23: 149-156.

http://dx.doi:10.1016/j.jmapro.2016.05.014.

6. Liu, Y. K.; Zhang, Y. M. 2013. Control of 3D weld pool surface, Control Engineering Practice 21: 14691480 . http://dx.doi:10.1016/j.conengprac.2013.06.019.

7. Kiaee, N.; Aghaie-Khafri, M. 2014. Optimization of gas tungsten arc welding process by response surface methodology, Materials \& Design 54: 25-31. http://dx.doi:10.1016/j.matdes.2013.08.032.
8. Viano, D. M.; Ahmed, N. U.; Schumann, G. O. 2000. Influence of heat input and travel speed on microstructure and mechanical properties of double tandem submerged arc high strength low alloy steel weldments, Science and Technology of Welding and Joining 5: 26-34. http://dx.doi:101179/stw.2000.5.1.26.

9. Farhat, H.; Oguocha, I. N. A.; Yannacopoulos, S. 2009. Effect of welding speed on weld quality and microstructure of tandem submerged arc welded X80 pipeline steel, Proceedings of Joining of Advanced and Specialty Materials; 2009 Oct 25-29; Pittsburgh, Pennsylvania: Materials Science and Technology.

10. Srivastava, B. K.; Tewari, S. P.; Prakash, J. 2010. A review on effect of arc welding parameters on mechanical behaviour of ferrous metals/alloys, International Journal of Engineering and Technology 2: 1425-1432.

11. Tasalloti, H.; Kah, P.; Martikainen, J. 2014. Effects of welding wire and torch weaving on GMAW of S355MC and AISI 304L dissimilar weld, International Journal of Advanced Manufacturing Technology 1: 197205. http://dx.doi:10.1007/s00170-013-5484.

12. Maksuti, R.; Mehmeti, H.; Imeri, S. 2009. Correlation of microstructure and hardness of two-pass submerged arc welds of line pipe steel X65, International Journal of Microstructure and Materials Properties 4: 347-355. http://dx.doi:10.1504/IJMMP.2009.03114.

13. Durgutlu, A. 2004. Experimental investigation of the effect of hydrogen in argon as a shielding gas on TIG welding of austenitic stainless steel, Materials \& Design 25: 19-23. http://dx.doi:10.1016/j.matdes.2003.07.04.

14. Juang, S. C.; Tarng, Y. S. 2002. Process parameter selection for optimizing the weld pool geometry in the tungsten inert gas welding of stainless steel, Journal of Materials Processing Technology 122: 33-37.

15. Kumar, S, Shahi, A. S. 2011. Effect of heat input on the microstructure and mechanical properties of gas tungsten arc welded AISI 304 stainless steel joints, Materials \& Design 32: 3617-3623. http://dx.doi:10.1016/j.matdes2011.02.017.

16. Esme, U.; Kokangul, A.; Bayramoglu, M. et al. 2009. Mathematical modeling for prediction and optimization of TIG welding pool geometry, Metalurgija 48: 109112.

17. Lucas, W.; Bertaso, D.; Melton, G.; Smith, J. S.; Balfour, C. 2012 Real-time top-face vision based control of weld pool size, Welding International 26: 243-250. http://dx.doi:10.1080/09507116.2011.581336.

18. Zhang, G. J.; Chen, S. B.; Wu, L. 2005. Intelligent control of pulsed GTAW with filler metal, Welding Journal 9-16.

19. Zhao, D. B.; Chen, S. B.; Wu, L.; Dai, M.; Chen, Q. 2001. Intelligent control for the shape of the weld pool in pulsed GTAW with filler metal, Welding Journal 253260.

20. US patent No US2010/0012638. Fortain J.M.; Revel O. TIG braze-welding with metal transfer in drops at a controlled frequency, Jan. 21, 2010.

21. Baskutis, S. 2013. Weld control possibilities in arc welding, JVE Journal of Vibroengineering 15: 159-164.

22. Hirata, Y. 2003. Pulsed arc welding, Welding International 17: 98-115. 
23. Eren, H. 2007. The mechatronics handbook. CRC Press, Florida

24. Bendikiene, R.; Janusas, G.; Zizys, D. 2015. Comparative analysis of microstructure and quality of gas metal arc welded and shielded metal arc welded joints, Mechanika 21: 323-328. http://dx.doi:org/10.5755/j01.mech.21.3.9861.

25. Vora, J. J.; Badheka, J. V. 2017. Experimental investigation on microstructure and mechanical properties of activated TIG welded reduced activation ferritic/martensitic steel joints, Journal of Manufacturing Processes 25: 85-93.

26. Giesserei. 1940. Theory of the Solidification of Castings.
R. Bendikiene, S. Baskutis, J. Baskutiene,

L. Kavaliauskiene

\section{MONITORING OF WELDING PROCESS \\ PARAMETERS IN GAS TUNGSTEN ARC WELDING OF CARBON STEEL WELDMENTS}

\section{S u m m a r y}

Results of present study show the possibilities to monitor and control the automatic gas tungsten arc welding process using additional filler rod, and investigate the evolution of microstructure and the mechanical characteristics of carbon steel weldments joint under the different welding parameters: welding current, arc voltage, and travel speed. Three types of weldments were produced and tested: buildup welds, U-grooved samples, and butt welds. Penetration and depth of heat affected zone in all types of welds are influenced especially by the welding current. Dendrite structure formed after welding gives a good indication of the thermodynamic processes during liquid metal solidification, welds are free from defects. The welded joints showed that crystal orientation and shape in the weld zone depend on thermodynamic processes during solidification and welding mode. The frequency and size of the successive droplets of the molten metal from the filler rod has been registered by piezoelectric sensor and due to the collected data the welding parameters and herewith the geometry and structure of heat affected zone and weld bead have been controlled.

Keywords: gas welding; solid filler rods; sensors; metal transfer; butt welds; building up by.

Received November 28, 2018 Accepted February 15, 2019 